\title{
A no smoking ward is possible
}

\author{
A. PANG \\ Nursing Officer, Central Middlesex Hospital, London, N.W.10
}

I AM very pleased to have the opportunity to say a few words at this symposium on "A no smoking ward is possible'.

When I was appointed to Sister-in-Charge of a Medical Unit which includes cardiology, the Coronary Care Unit, and general medicine, at the Central Middlesex Hospital, I myself was amazed to find there was no smoking in the wards. The prime reason for this was the endless efforts made by the medical staff with the added support of the nursing personnel.

The patient on admission is informed by the doctor and the sister that no smoking is permitted in ward area. We also talk to their relatives and ask for their co-operation. On the whole, they are very keen and pledge their full support. They are asked not to bring in cigarettes and matches. Since the 'No Sale' of cigarettes on hospital premises, it makes our job a little easier. 'No smoking' notices are displayed in waiting-rooms, corridors and departments, informing visitors that they are not permitted to smoke. Notices and posters are also displayed in wards to discourage patients from smoking. Our own staff are not permitted to smoke in public when wearing uniform.

I am sure most of our patients are aware of the injury they are inflicting on themselves when they smoke but it is a habit and just like a drug to them and they need help to give it up. We not only make them aware of injury to their own health but also of the harm they will cause to the other patients as all are trying hard to give it up. It is all too easy for us to say, 'you must not smoke' but we must realize it is not easy for the patient who is a smoker and is now in strange new surroundings. They are sometimes nervous, lonely, worried about their illness and are away from their family so they need all our support and encouragement when informing them of the reasons why they must give up smoking.

We encourage them to get to know each other and to talk to each other about their experiences in giving up smoking. There are many patients who have given up smoking and when they return to the out-patient department we invite them to come along to chat with the patients, in the ward. For example, one of the patients was a very heavy smoker for over 20 years. He was admitted to the ward with acute or chronic bronchitis. He gave up smoking when he was in the ward. I saw him 3 months after he was discharged, he looked a different man. He told me that now he could stand up straight. A week ago, he managed to take his wife to a dance, that he had not been able to do for years. I asked him to have a chat with the patients in the ward. He told them how much he had appreciated that we had stopped him from smoking. Now his health was much better and his social life was much improved.

Of course, there are exceptional cases, such as terminal cases and patients admitted with an overdose, where the nature of the complaint is very distressing. We do allow them to smoke under supervision, but we segregate them by putting them in the side wards.

I talked to fifty patients from the other medical wards where smoking, although discouraged is not forbidden. Twenty-eight of them were non-smokers, the other twenty-two smokers. Twenty of the nonsmokers agreed that there should be no smoking in the ward. Three of them are very strongly against smoking taking place in the ward. They said that they had given up smoking a few months ago and they did not like to be in a smoking atmosphere. Eight of the patients did not mind either way.

Seventeen of the smokers would be willing to give it a trial and stop smoking if the sister or doctor wanted them to. They all knew the hazard of smoking. Three of them said that it was impossible to give it up because they were so bored in hospital. They said that if smoking had not been permitted in the ward they would have smoked behind the Sister's back, in the toilet etc.

It is our impression, although we are not $100 \%$ successful in our own ward, that the majority of patients do stop smoking. In order to find out how much secret smoking was in fact going on, the Medical Staff helped me to measure the COHb of patients from our own ward to compare with another medical ward. The blood tests were done at the same day and at the same time. The results are as follows:

(a) Our ward

Mean \% COHb smokers $\quad 1.4$

Non-smokers 
(b) Other medical ward Mean \% COHb smokers Non-smokers

disease. I am sure that it is right for us to try to discourage our patients from smoking. At the end, I would like to say ' $I$ hope in the near future that we might be able to say a no-smoking hospital is possible'.

\section{Discussion}

DR J. W. Paterson (Brompton Hospital): I am sure I would find it impossible to resist giving up smoking if $I$ were on your ward; but can you tell me what action do you take if a staff member breaches your regulations and smokes, and what do you do if you find a patient smoking when you have advised him against this?

Miss A. Pang (Central Middlesex Hospital): It is surprising, but really $I$ have never seen one of my patients light a cigarette inside the ward yet.
Dr Paterson: But what is the policy if a member of staff smokes where the patients can see him?

Miss PANG: I do not think this has ever happened in our own ward, but if it did I would have to talk to them and try to persuade them to give it up. I think we should let them know it is their duty really to show an example to their patients. 